\title{
BASES Y FUNDAMENTOS PARA UNA APROXIMACIÓN SOCIOLÓGICA A LA VEJEZ
}

\author{
Pedro Sánchez Vera \\ Departamento de Sociologin e Historia Económica \\ Universidad de Murcia
}

Restum

Es tracta de realitzar una aproximació a la sociologia de la vellesa. Per a això, s'exposen en aquest article algunes de les reflexions $i$ dels arguments més globals que des de la sociologia es fan sobre la vellesa i la seva relacio amb la societat ila producció. S'ussenyalen també les relacions de la vellesa amb les uplusvalues socials", el "temps", el concepte de "generación $i$ "les edats", La "mort" $i$ el "cos". Els factors diferencials dintre de la poblacio anciana són els més importants $i$ els que cal ressaltar dins una sociologia de la vellesa.

Resumen

Se trata de realizar una aproximación a la sociologia de la vejez. Para esto, se exponen en este articulo algunas de las reflexiones y de los argumentos más globales que desde la sociologia se hacen sobre la vejez y su relación con la sociedad y la producción. Se indican también las relaciones de la vejez con las splusvalias sociales", con el "itiempo", con el concepto de "generación" $y$ "las edades", con la "muerte" y con el "cuerpo". Los factores diferenciales dentro de la población anciana son los más importantes y los que se deben resaltar dentro de una sociologia de la vejez.

Abstract

This article is an approach to the sociology of the old age. To realize this approach, it exposes some of the more global thoughts and arguments which from sociology are made about the old age and its relationship with society and production. It also underlines the relationships of the old age with the usocial increased values", with utime", with the concept of "generation" and "the ages", with "death" and with the "body". Those differential factors within the elder population are the most important to underline within a sociology of the old age. 
«Papers": Revista de Sociologia

\section{INTRODUCCION}

Celebrándose en este año 1993 el año europeo de las personas de edad avanzada y de la solidaridad entre las generaciones (Barenyes, M. P., 1992, pp. 75-76), y a través de este número monográfico de la revista PAPERS, es hora de hacer una recapitulación sobre una serie de ámbitos sociales y culturales que definen y caracterizan a la vejez; sin embargo, en la vejez no todo son rasgos comunes sino que, bien al contrario, con frecuencia lo heterogéneo se hace rasgo dominante.

En el presente artículo intentamos resaltar la heterogeneidad y diversidad que caracteriza a las poblaciones ancianas. De manera intencional hablamos de "poblaciones" con el fin de resaltar lo que de diferencialidad existe en las mismas. Parece que ahí radica parte del quehacer del sociólogo: describir y analizar las diferencias que la realidad social objetiva contiene. Y esta tarea sociológica se hace a veces conveniente o necesaria para matizar o aclarar pareceres divergentes, contrarrestar representaciones y/o enfatizar el alcance de conceptos $\mathrm{e}$ ideas. En las páginas que siguen hemos querido hacer un poco de todo esto. Frente a la hegemonía conceptual y práctica de la tercera edad como "grupo", cuando no decididamente como "grupo social", intentamos referir ésta a sus fundamentos sociales. Ahí y no en otro lugar podremos conocer la teleología de estas representaciones sociales homogeneizadoras sobre la tercera edad, y escudriñar en la naturaleza social de la segmentación que caracteriza a los ancianos.

La población anciana 0 , más exactamente, las poblaciones ancianas son abundantes o no. Todo depende de una valoración arbitraria cuantitativa que se establece o por la cual nos rejimos para considerar si un cuantum es o no elevado, o si sencillamente se comporta conforme a medias o estadisticas de diferente tipo. De otra parte, son decisivos los criterios o supuestos conceptuales de partida. Según éstos, la cantidad de ancianos será acorde con los indicadores objetivos adoptados. En el caso de la población anciana, el concepto que determina el cuantum viene definido tambien arbitrariamente. Los ancianos son parte de la población no activa, al estimarse la edad laboral en España en sesenta y cinco años, aunque en proceso de revisión. De esta manera, y en general, en la mayor parte de países desarrollados toda persona que lleguc a esa edad deja de ser "población activa", esto es: deja de tener relación directa, legal y estadística con el trabajo, pasando a engrosar el subgrupo de no activos, denominado de "jubilados y pensionistas".

Los principios que fundamentan la convención arriba señalada se basan resumidamente en dos argumentos principales: el primer argumento es el que mantiene que esa decisión intenta dejar paso en el trabajo a las generaciones jóvenes. Según éste, se "sustituye» y se "renueva" una mano de obra por otra más 
joven y dinámica, pero eso sí, menos experta y que se supone hay que formar para que se haga cargo del sistema productivo y del mantenimiento de la sociedad no productiva. Este principio de la "socialización" de los jóvenes con el trabajo y la producción se sustenta a su vez en otros principios más generales: uno de carácter demográfico, cual es el del ureemplazo generacional" en el mundo de la producción; otro de carácter económico basado en el rendimiento del "capital humano"; y otro de caracter educativo basado en la «instrucción práctica" y en la "responsabilidad societaria". Según estos principios, la producción se ve continuamente renovada y actualizada por la vía de los imputs y de los outputs que se producen en los "recursos humanos" en relación con el sistema productivo, constituyéndose los recursos humanos en factor básico del rendimiento y de la producción. Y trasladando el utestigo" de la organización social (cultural, política y productiva) de generación en generación. El segundo argumento por el que se postula la jubilación, una vez Ilegada la mágica edad de los sesenta y cinco años, es el del umerecido descansom. El anciano del siglo XIX no tenía derechos y trabajaba hasta que podía, sufriendo un proceso progresivo de descualificación profesional, y donde la vejez era igual a la pobreza, y a la ayuda de la familia o a la beneficencia de las institituciones. Las condiciones de trabajo tayloristas no hacen sino acelerar el envejecimiento físico de los productores y restar valor al trabajo de las personas ancianas. EI Welfare State consigue a mediados del siglo actual proteger por la vía de la "pensión" a los jubilados y a sus familias. Así, la ujubilación" es socialmente concebida como derecho y también como gracia o concesión del Estado y/o de sus gobernantes.

En relación con los dos argumentos caben y se han hecho muchas consideraciones críticas de diferente signo e incluso contradictorio. Resumiendo al extremo algunas de las principales, son éstas:

1. La jubilación de efectivos no siempre es sustituida en igual magnitud, bien sea porque el sustituyente sea la "tecnología" o porque sencillamente no hace falta ninguna sustitución de personas. Incluso en determinados trabajos u "oficios" no hay nada que reemplazar, pues justamente se trata de su cancelactón.

2. El mantenimiento de la población no productiva no depende sólo de los activos ocupados. Así, las tasas de dependencia demográfica quedan relativizadas para convertirse en un indicador social más, pues son muchos los no jóvenes que desean incorporarse al sistema productivo (v.g: mujeres). Y lo que es más: los ancianos, en realidad, no son mantenidos por nadie, sino por ellos mismos, que se han ido pagando a lo largo de su vida laboral y mediante su cotización anticipada su porvenir.

3. El trabajo es un bien escaso, y por tanto hay que prolongar (retrasar) la entrada de los jóvenes en el sistema productivo. De esta manera, el sis- 
tema educativo adquiere funciones no sólo instructivas (Moncada, A., 1976, 1979; Martín, J.-De Miguel, A., 1979).

4. La edad de jubilación es impuesta de manera objetiva al sujeto, sin haber sido consultado sobre orra posibilidad.

5. En muchas ocasiones la jubilación (pensión) es un logro social (regiones desfavorecidas), pero este principio no es generalizable desde el momento en que hay sujetos que desean seguir produciendo y que están en perfecto estado para ello.

6. Con las nuevas tecnologías se rompen las formas tradicionales de transmisión de la cultura estas favorecen a los jóvenes (más motivados y con conocimiento instrumental) y a los dotados de "plusvalías sociales" (que son los que más fácilmente han terido acceso a ellas o a su mejor conocimiento).

7. La "secularización" de la ética del trabajo dota a éste de cometido instrumental en las generaciones jóvenes, dejando de ser un valor en sí mismo (Castillo Castillo, J, 1989).

Las importantes mutaciones socio-económicas acaecidas en los países desarrollados han ido reduciendo paulatinamente la edad media de vida activa de los sujetos, e imponiendo unos mayores tiempos de acceso a la misma, a la par que dilatando el tiempo de duración de la "jubilación", siendo previsible una mayor reducción del tiempo de vida activo de los sujetos, fundamentando de esta manera lo que se ha venido en llamar la "sociedad" o la "civilización del ocion (VV. AA., 1968), sociedad que en el fondo y en razón de la procedencia y trayectoria social, no hace sino acrecentar las diferencias sociales entre grupos y clases sociales (ibídem, pp. 89 y ss. y VV. AA. 1971). Esta sociedad del ocio referido a la tercera edad y en atención a la duración de su tiempo de ocio y a la gran transformación cultural en ella acaecida se ha venido en llamar, emulando a Thornstein Veblen, "la nueva clase ociosa", pues en ella se producen nucvos fenómenos que antes no existian (viajes, ocio, juegos...). Resulta chocante ver cómo los grupos de tercera edad - sabedores de las connotaciones peyorativas del término "ocio" - evitan este vocablo en sus denominaciones o en la relación de sus objetivos, sustituyéndolo cuando es obligado por el de "tiempo libre», que es más liviano y en gencral connota menor "culpabilidad", pues evita y sustituye la parte individual de inactividad, pereza y otras connotaciones, por esa otra mucho más global y transitoria que es la de "tiempo libre" (que se supone parcial y despues de ciertas tareas). No es de extrañar esta evitación en lo posible del término ocio (y de su uso: la ociosidad), pues es moneda común pensar que los ancianos viven de las utransferencias" de otros sectores productivos y de las aportaciones del patrimonio nacional del Estado, siendo a su vez unos grandes consumidores de servicios 
y de salarios indirectos (salud, ocio, transportes). De esta manera, los ancianos -que dentro de las grandes difcrencias que entre sí existen, y que defendemos como factor diferencial entre ellos, gozan en general de un aceptable nivel de vida. Así se transmite la idea de que los ancianos cuestan muy caros, pues mantener un nivel decoroso de vida para ellos es igual a reducirlo de los otros (máxime cuando lleguen a ancianos las generaciones numerosas procedentes del babi boom).

\section{LAS PLUSVALIAS SOCLALES Y LA VEJEZ}

En toda sociedad hay sujetos que se sitúan mejor que otros en razón de su prestigio, de su poder, de su rango o senciliamente del reconocimiento social. La "plusvalia" de los sujetos en sociedad viene dada por un cúmulo de factores, entre los que hay que destacar los siguientes:

1. El aspecto físico, esto es: la corporeidad (sujeta a modas, modos y valores) que es el sumatorio de salud, físico natural, y vestido y aditamentos.

2. La personalidad individual. Que es producto de un gran número de factores, entre los que hay que destacar el «encanto" personal, producto de un buen número de valores sociales que varían según el tiempo, el territorio, el sexo, la edad y la cultura. A estos hay que añadir: la imaginación, la creatividad, las buenas costumbres, el refinamiento social y otros aditamentos que conforman el "encanton de la personalidad individual.

3. Los conocimientos adquiridos. Estos son objeto de plusvalía social en razón de la prominencia social de su función, de su prodigalidad o escasez, o sencillamente porque culturalmente son objeto de valor social, y por sí mismos en tanco que añaden valor a otros factores. En general son un instrumento de plusvalia social ligado al trabajo.

4. La información a la que el sujeto tiene acceso. La naturaleza social de la información otorga plusvalía a quien la posee, pues ésta es mercancía de cambio e instrumento de interacción social. Muy ligada hoy a la posesión de las nuevas tecnologías o al acceso a éstas.

5. Las redes de interacción social a las que de forma directa (amistad, parentesco, afinidad, etc.) o indirecta (relación profesional), o ambas a la vez, accede el sujeto, bien de forma dirigida o intencional (v. g: hacerse miembro de un club, asociación, partido) o de manera arbitraria y azarosa como producto de la acción social objetiva y/o subjetiva. La importancia de estas "redes" en el acceso y control de la información son viejos 
"Papers": Revista de Sociologia

temas de la sociología, así como la importancia de los códigos simbóli$\cos$ de acceso a dichas redes.

6. Las riquezas materiales acumuladas o de las que se es usufructuario. Éstas, bien administradas y disfrutadas, aportan seguridad y distinción, y en la mayoria de los casos bienestar social.

7. La estirpe, el apellido o el origen social. Éstos aportan como valor la ureferencia" y la "territorialidad".

8. El espacio. A veces la pertenencia a un espacio o territorio determinado al que se adscriben valores sociales dominantes o culturalmente hegemónicos añade plusvalía social al sujeto o a los sujetos a él pertenecientes.

9. El sexo como factor cultural produce impronta en todas las relaciones sociales. Un sexo utiliza, al menos teóricamente, con mayor habilidad sus encantos físicos que el otro en la "negociación social". La escasez o el desequilibrio de sujetos de un sexo determinado en relación con los del otro sexo es objeto de plusvalía (este factor está relacionado con la edad).

10. La edad es un valor que varía espacio-temporalmente. En cualquier caso, en las sociedades modernas los niños - como bien escaso- tienen plusvalía propia, y los jóvenes, como mercancía y "potencialidad". Los desequilibrios generacionales en determinados grupos etáneos aportan, por la escasez de determinados grupos, plusvalía social demográfica.

I1. El estado civil introduce un especial sesgo en todas las relaciones sociales, siendo éste un factor de normatividad que atraviesa toda la vida social del sujeto, e introduciendo junto al resto de factores anteriores un elemento más de estatus y/o de plusvalía social.

Del juego de todos estos factores y su particularización en cada sujeto o "actor" social, a éste le deviene su estatus y su imagen social.

Referido al anciano, desde luego, existe una "imagen" social de éste. Esa imagen es el sumatorio de muchos de los elementos arriba mencionados y concretados en un colectivo socialmente definido por su función social y consiguientemente por el lugar que se le asigna en la estratificación social. Sin embargo, esto no nos debe hacer olvidar las grandes diferencias que hay entre los ancianos. Es más, esas diferencias son anteriores (y se acumulan) a la vejez. $\mathrm{La}$ imagen del anciano, siendo concreta, sin embargo, es también objetivizadora. La percepción social del anciano es el sumatorio de muchos elementos que son los que "construyen" (Berger-Luckmann, 1972) una imagen que es producto de la propia sociedad, esto es: de las instituciones que se encargan de ellos, del propio "aspecto" de los ancianos, que unen a su decrepitud un frecuente y maniffesto desaliño en el vestir, la propia situación ociosa y/o "anómica». La representación social del anciano a la que tanto y tan eficazmente contribuyen 
determinados análisis y discursos catastrofistas sobre la sociedad envejecida (Sauvy, A., 1960), dentro de un general "galimatías ideológico" (Izquierdo, A., 1987, pp. 39-49), no hacen sino acentuar la imagen de «inutilidad social» y de "ocio pensionado", amén del gasto que suponen los ancianos o de las consecuencias sociales o "factores espirituales" del envejecimiento (ibidem, Sauvy, pp. 126-128).

Justamente cuando se habla de la tercera edad (término al que nos referiremos después con mayor profusión de detalles), se está intentando transmitir la imagen o la sensación de una "vejez activa", frente a la "vejezez enferma" que se ha venido en llamar recientemente "cuarta edad". La gran feminización de la tercera edad no contribuye a mejorar la imagen social del anciano. La imagen, en cualquier caso, se impone de manera objetiva al sujeto y es la parte dura de la percepción social (Sánchez Vera, P., 1987). Como en el espejo, los sujetos perciben una determinada imagen. Los ancianos en general tienen poco amor a los espejos (que es lo que ven los demás de uno mismo), pero no por eliminarlos se evita ser visto por los demás. Lo lamentable de todo esto es que parte de la supuesta nueva identidad colectiva de la tercera edad proviene del sumatorio de muchas de estas imágenes sociales.

\section{SOCIOLOGIA DE LAS EDADES Y DE LA VEJEZ}

La sociología de las edades es, desde luego, una parte del análisis sociológico que tiene por objeto el estudio de cómo la sociedad condiciona y define socialmence al ser humano en sus diferentes procesos vitales marcados por la cdad. De esta manera, los conceptos sociales ligados a las diferentes edades vienen histórica y culturalmente condicionados y definidos. En la interacción sujeto-sociedad en relación con el tiempo objetivo se ejercita un determinismo social que se impone de manera objetiva al sujeto y que lo va condicionando-dirigiendo por unos particulares procesos de "socialización". Procesos que se hacen, o tienen rasgos comunes con sus "con-géneres"; de esta manera inevitable hay formas de identiffcación colectiva que son a todas luces objetivas. Esa identificación se nutre de dos factores básicos: la biografía colectiva (vivencias) y la común problemática. Estos dos factores, siendo decisivos, pueden hacer olvidar, sin embargo, dónde radica la sustantividad de la diferenciación social. La edad (al igual que el sexo), forma parte del constructo social que definc al estatus. No obstante, no hemos de olvidar que la "edad" es una "condición" (socialmente devenida) amén de un "accidente». Elevar ésta (la edad) a variable de primera categoría puede llevarnos a que los árboles no nos dejen ver el bosque. Esto es: a la "psicologización" del fenómcno, a mi parecer, exacerbadamente extendida. La psicologización de las edades conduce entre otras cosas a 
soslayar otros aspectos de diferenciación en favor de lo "común». Igualmente, favorece cierto tipo de descriptivismo de los "hechos" colectivos, omitiendo el análisis (causas y efectos) de las "realidades" sociales, en las que, a mi juicio, se producen importantes e inexplicables "olvidos" de algunas de esas realidades o de parte/s de la/s mismas. Esto que observamos, en modo alguno queremos decir que sea parte de la incipiente sociología de las edades - más bien al contrario-, sino que es frecuente y hegemónica dentro de las representaciones sociales sobre las edades y particualmmente sobre la vejez, que es la que nos ocupa.

No solamente hay diferencias sociales por edad, que las hay y muy importantes como más arriba señalamos, sino que hay realidades distintas (y grandes) dentro de la/s poblacion/es anciana/s. Esas diferentes realidades sociales respecto a los ancianos acrecientan el interés sociológico de su conocimiento. Pero lo que es más importante: enfatizan cl alcance que tienen otros factores comunes (dentro del de la edad) como puede ser el de la situación económica, el de la autopercepción o sencillamente otros elementos culturales. Justamente, estos factores culturales constituyen con harta frecuencia la esencia o causa práctica de la "diferenciación" con respecto a otros grupos etáneos o generacionales, que son la base de la marginación social en la que se encuentran respecto a la sociedad, y son el fundamento y la definición de la usubculturan del anciano. Desde luego, sin esos mimbres, difícil es tejer un cesto: el de una sociología de la vejez con entidad propia; esto es: con anclajes analíticos. De esta manera, una sociología de la vejez debe partir de sociedades y de poblaciones ancianas concretas que nos permitan establecer y remarcar la taxonomía de la diferenciación desde una perspectiva sociológica integrada.

Uno de los tradicionales temas de la sociología de la educación ha sido el de la segregación de las edades. Por una parte, los sistemas educativos estructuran sus currículos sobre unos estadios de maduración (piagetianos fundamentalmente) que si bien son ciertos desde los postulados de una epistemología genética (Palop, P., 1981), resultan exacerbados en la práctica educativa al separarse definitivamente por grados y edades a niños y jóvenes. Por otra parte la dinámica social reduce cada vez más los ámbitos de interacción social entre generaciones a dominios privados (familiares sobre todo), produciéndose aún cn el ámbito familiar una más que notable pérdida de relación con personas de diferentes edades, tal como acontecía en la familia cxtensa y en la numerosa (hermanos de edades distintas). Este hecho resulta tanto más curioso cuanto que son más las personas que llegan a edades avanzadas como consecuencia del incremento en la esperanza de vida. Y resulta también más patético y sorpresivo por cuanto es la primera generación de nietos que suele conocer a todos sus abuelos.

De otro lado, la mayor madurez de los jóvenes y menor senescencia de los ancianos se ven incursas en procesos de cambio social intenso y rápido que por 
una parte (es el caso español) avivan las diferencias intergeneracionales, y por otra magnifican el valor innovación y cambio. De esta manera, a las tradicionales discriminaciones por sexo, taza, pobreza y otras, se va incorporando sutilmente una nueva y más inflexible que es la discriminación por edades ( $\mathrm{S}_{\mathrm{a}-}$ grera, M., 1992, pp. 9-16). Para este autor, desde una perspectiva casi militante, el "edadismo" debe ser combatido a través de la desmitificación del mito de la uadultez» (ibídem, p. 16-18).

\section{EL CUERPO, SOCIEDAD Y VEJEZ}

Los sujetos son en parte lo que su aspecto denota (el cuerpo como escenario). El paso del tiempo, aunque deja huelias físicas y condiciona la personalidad de cada ciudadano, es el factor más objetivo de referencia social. Pues cada sujeto tiene un cuerpo, en el que aunque con más o menos importantes márgenes de error, se puede determinar el impacto del tiempo sobre su cuerpo (edad biológica). De esta manera, del cuerpo socialmente informante, es difícil sustraerse, ya que es el reflejo de una historia o biografía individual, de unos rasgos o caracterizaciones de los grupos próximos al sujeto en cuestión, y el reflejo de una condición y estatus social individual y de clase social. De esta manera el cuerpo es un elemento de alto valor metafórico. La sociología del cuerpo está por hacerse; así lo señalan autores como Turner que entiende que el cuerpo puede y debe convertirse en una parte central de la investigación sociológica (Turner, B. S., 1989, pp. 57-89), pues el cuerpo es fundamental para los órdenes micro y macro dc la sociedad.

Este autor va más allá en sus apreciaciones y sugiere la posibilidad de reinterpretar a Goffman (y con él a algunos otros interaccionistas: Mead, Garfinkel). Para Turner, los interaccionistas simbólicos admiten la existencia de una doble situación, pues de un lado existe un contraste entre el yo y la sociedad, pero tambien el yo se hace realidad por medio de la actuación. Así, la representación del cuerpo en la vida diaria (cotidiana) es fundamental para la actuación del yo. De esta manera no habrá que interpretar la sociología de Goffman como el estudio de la representación del yo en los agrupamientos sociales, sino como "la actuación del yo a través del instrumento del cuerpo socialmente interpretado" (ibídem, p. 68). Por consiguiente, el cuerpo es el blanco también de los rituales de degradación de la exclusión social, que en el caso de la vejez es uno de los factores de representación social.

Una sociología del cuerpo debería incluir a juicio de Turner, entre otros elementos, una "sociología de la desviación y del control", pues las mortificaciones del yo están unidas a las del cuerpo. Distinguinendo entre la desviación de las apariencias del cuerpo (sonrojos, rubores, secreciones no deseadas) su- 
jetas a la vigilancia cultural y las desviaciones del cuerpo interior (la afección y la enfermedad), que son también objetos de evaluación moral. Así Turner entiende que "la sociología del cuerpo como vehículo de información acerca del yo se dividiría en torno de la estigmatología de la apariencia exterior y de una teratología de las estructuras deformes" (ibídem, p. 68). Igualmente considera factores básicos las dicotomias "privado-públicon y "masculino-femenino\%. Ciertamente que con muchas de las apreciaciones de Turner, dificilmente podemos estar de acuerdo, como por ejemplo cuando entiende que la sociología del cuerpo es sociología política, aunque podamos compartir también parte de sus argumentos.

Por otra parte, el cuerpo posee un alto contenido simbólico, esto es cultural y social, siendo la característica más próxima del yo social, pero también es un elemento clave de la identidad individual. El cuerpo, como señalan los interaccionistas, forma parte de la representación social del yo tanto individual como social, y es a la vez una pieza definitiva de la interacción social (Mead, Goffman). Si bien hacemos ejercicio de soberanía sobre el propio cuerpo, también hay factores que hacen vivir el cuerpo como alienación. La mejora del aspecto físico a través de trabajos faciales o de reparaciones corporales y el propio carácter simbólico de la enfermedad son algunos factores que como pone de relieve Turner hacen dificil saber realmente qué es el cuerpo, "pues siendo material también es una metáforan (ibidem, p. 32).

\section{EL TIEMPO Y LA VEJEZ}

A la sociedad le cuesta ver, sin embargo, que cada sujeto, sea de la edad que fuere, antes fue niño, joven y así sucesivamente. De esta guisa, se gestan formas larvadas de insolidaridad social, siendo la desigual percepción del tiempo - que varía según la historicidad de las sociedades, según la edad y según otros factores sociales objetivos y subjetivos - el factor más determinante de esa insolidaridad o "subjetivismo" social. Este subjetivismo insolidario es a la sazón espiritualista, pues viene a ver a cada persona como es en ese momento de su edad, pensando que siempre ha sido así, como si no hubiera "cronos". La fijación de los adultos, y particularmente de los ancianos, por hacer referencia a tiempos pretéritos de sus biografias, es en el fondo una "demostración social" de que también se fue joven (niño, etc.). De esta manera refuerzan su "yo" histórico a la vez que crean elementos de "continuidad social" en el sentido de hacer ver que los tiempos en lo esencial no han cambiado tanto, es decir que los jóvenes, por ejemplo, siguen haciendo "lo mismo" que ellos hacian, pero de formas diferentes.

Cuando relacionamos las generaciones con el "tiempo" vemos, como hemos señalado más arriba que éste es social e individualmente percibido de for- 
ma diferente. Las generaciones de niños de hoy, presumiblemente tendrán también una percepción del tiempo más rápida que la que tuvieron los niños de hace cincuenta años. Es un tiempo mucho más uocupado" y previsiblemente pase más rápidamente.

Pero junto a esto, hay que observar también la rapidez con la que el tiempo pasa en el devenir de los años. Conforme nos hacemos mayores, el tiempo se hace efímero porque es teleológico. A los adultos se les hace dificil darse cuenta de que las nuevas generaciones no han vivido los acontecimientos que ellos tuvieron ocasión de vivir, por razón exclusivamente de la edad. La "subjetivización" del tiempo tiene un excelente correlato en la pérdida de teferentes temporales concretos y afinados, que lleva a los sujetos adultos a pensar que todo el mundo tiene idénticas referencias temporales.

Referido a ta vejez, se hace necesario conocer mínimamente la importancia del tiempo en la vida del anciano. Con independencia de las reflexiones globales sobre el tiempo, el sujeto y la sociedad (Ramos Torre, R., 1992), no cabe duda de que nos encontramos ante un hecho que es desigualmente percibido por los sujetos, en función de diferentes variables. Variables entre las que habría que destacar de un lado la propia edad del sujeto perceptor (el tiempo corre de diferente forma según la edad), la cotidianeidad de cada cual, y el momento histórico que le toca vivir. Por supuesto, ninguna de estas variables son independientes sino que están concatenadas entre sí y relacionadas con otras tantas (actividad física e intelectual, hábitat, hontanat de vida, etc.).

Dentro de la teoría sociológica contemporánea, se hace continuo hincapié en la historicidad de la acción social y de las relaciones sociales, existiendo un alto grado de consenso en la crítica al funcionalismo por su tendencia cstática atemporal y ahistórica (Martins, H., 1992, p. 183), al igual que por otra parte existe un alto grado de reconocimiento al análisis fenomenológico de la vida cotidana como un espacio básico y fundamental donde enmarcat e interpretar el ziempo (ibídem, p. 192 y ss.). Por otra parte, no puede pasar desapercibido como las estructuras de lo cotidiano son un sector de la vida social altamente resistente a la historicidad, tal como ha puesto de relieve Lefebvre, la cotidineidad está impregnada de una gran rigidez, siendo la repetición y la ciclicidad los modos temporales dominantes (Lefebvre, 1984). Se nos ocurre que el peso de la cotidianeidad es cspecialmente subyugante en la vejez; su propio microcosmos social condiciona la percepción del tiempo. Fenómeno complejo de analizar éste - el de la percepción del tiempo en la vejez - tanto en lo teórico como en lo práctico, pues si de un lado el tiempo se estira en la vida cotidiana del anciano (en su privacidad y evanescencia), de otro se hace teleológico y futilizante.

Ios términos de "viejo" o "anciano" son objeto de plusvalía cuando de determinados bienes materiales se trata, pero no hay plusvalía social cuando los vie- 
jos son sujetos con nombres y apellidos. Se da la paradoja que mientras el tiempo genera plusvalía en ciertos bienes materiales que se ven revestidos y determinados por su singularidad, esto no ocurre cuando de personas se trata. En este segundo caso, la única posibilidad de plusvalía es la individualmente generada en razón de una biografia personal revestida de aditamentos sociales (posición), físicos (aspecto) e individuales (personalidad). Cualquier posibilidad colectiva de generar o de ser objeto de plusvalía por los viejos es descartada por el propio sistema social. Pues al "aparcar" dicho sistema al anciano (y a la anciana) en la trastienda del sistema productivo, priva a los viejos de la posibilidad de aparecer en cl escenario social como mercancía con valor añadido. Siendo la uexperiencian valor de cambio, sin embargo no lo es de uso en el caso de los ancianos como colectivo.

la introducción de las nuevas tecnologias en el escenario laboral no hace sino incrementar las diferencias por edad y estatus social. Los jóvenes más próximos y socializados con las nuevas tecnologías ( $y$ con mayor formación) alcanzan con facilidad a comprender instrumentalmente su manejo, viendo con ello mejorar su prestigio y/o su posición taboral. Los adultos con menor ambición y motivación por las innovaciones, así cómo con cierta pereza instrumental, ven peligrar ciertas posiciones de poder "de facto" en el interior de las organizaciones. En el caso de los ancianos, las nuevas tecnologías son, en no pocas ocasiones, también una amenaza de jubilación anticipada o de vejez prematura. Éstas cancelan el viejo principio de la transmisión generacional de la cultura, por cuanto su ritmo inovador es continuo e incorporan un factor nuevo de segregación social.

Sin embargo, lo hasta aquí expresado puede hacer pensar en una representación colectiva de la ancianidad o de la vejez, cuando justo lo que defendemos es lo contrario. No son los ancianos un grupo social como con frecuencia se nos quiere hacer ver. Volveremos a esto más adelante.

Con respecto a la situación, más arriba explicada (las cosas como objeto de plusvalía), tiene explicación en una sociedad que intenta recuperar una cierta historia individual y colectiva de la que se ve expropiada. El tener una historia familiar, o sencillamente tener historia, da rango a quien la detenta. Así, en la sociedad hay quienes poseen y quienes no una historia. Ser poscedor de una cierta historia o tradición ennoblece al usufructuario. Esa historia puede ser familiar, de estirpe, territorial o de clase social. Las diferencias entre los sujetos vienen dadas entre otras cosas por tener o no tener una historia. Quien o quienes tienen historia "son" o "existen" socialmente, a diferencia de quien o quienes no la poseen.

Los pobres, los desarraigados, los excluidos del sistema social son personas sin historia aunque, claro está, con biografía (causas sociales de su situación de marginación). La sociedad urbana de una parte nos hace perder identidad (Sommer, 1974). De ahí una búsqueda de raíces. Los objetos de los que se ro- 
dean los sujetos condimentan el entorno y la realidad social de los actores de un alto contenido simbólico y representacional (Baudrillard, 1978). Al hablar de las bases sociales del gusto, Bourdieu nos da las claves para entender cómo éste se construye socialmente y de cómo entre el mundo de los objetos que nos rodeamos, merodea la búsqueda de la identidad individual, eso sí, en claves sociales (Bourdicu, 1988)

Cuando la innovación tecnológica, las modas y los diseños cambian a un ritmo tan vertiginoso como el cambio de la sociedad, lo antiguo cobra valor social. Si la "forma" del objeto es parte esencial de su valor (Baudrillard), la posesión de ese objeto nos aporta su plusvalía como aditamento de nuestra condición social ( $T$. Veblen), pues en su consumo establecemos una relación social.

Lo antiguo es viejo en esencia, pero dominan los signos externos de ser añejo o de su vejez. Ese objeto perteneció a alguien. Si ese alguien es próximo (familiar), mejor. Pues la herencia material nos conecta con el pasado colectivo y familiar. Con el vínculo al pasado a través de la posesión de los objetos, los sujetos quieren recuperar al menos una triple condición: A. La memoria social colectiva (la historia, las raíces). B. La historia familiar, el pasado, los recuerdos de infancia o de épocas pretéritas de su biografía personal (que ya no volverán). C. I a tradición de la estirpe familiar, la genealogía, el parentesco con personas de condición social elevada (hijosdalgo). Estos tres niveles (inconscientes la mar de las veces) de recuperación, se producen simultáneamente con harta frecuencia. Entre ellos hay también, sin embargo y a nivel analítico, prioridades, siendo el tercero el más social de los riveles y sin que por ello sean menos importantes los otros. Con él se remarcan las diferencias de origen social y de estatus.

Claro está que no todo lo viejo es antiguo ni, por tanto, tiene valor. Parte del valor de un objeto - es obvio- está en su prodigalidad o escasez. Por otra parte, está su función. Siendo la función lo más determinante en objetos concretos en tanto que alude a su valor de instrumentalidad, sin embargo, la función del objeto (v. g.: de consumo) implica una relación social en términos ideológicos (Baudrillard, 1978) y lo que es más: se constituye en soporte o excusa "de" o "para» dicha relación social. Dice Baudrillard que la función es el soporte del "signo" (Baudrillard, 1972). Así, la marca X aporta junto a la calidad y eficacia con la que réaliza su función, el valor añadido de su nombre, que aporta prestigio y legitimidad al sujeto que la posee ante círculos o grupos sociales previamente socializados con dichos códigos de legitimación.

Entre la "mundialización" de la cultura y la "privatización-individualizaciónn de la vida, quedan pocos espacios para la identidad social. I a vida social comunitaria, la cultura de la ciudad, del barrio, las asociaciones culturales, etcetera, son o podrían ser, factores de identidad social del anciano en mayor medida que lo son. Pues por su propia condición de segregado, su nivel de presencia y de participación en las distintas asociaciones civiles, es habitual- 
mente bajo (salvo en las elecciones). En estos espacios se puede recuperar una buena parte de la identidad de la cultura del anciano.

Resulta chocante que los términos que han cristalizado en los últimos años: tercera edad, o el menos afortunado cuarta edad (para referirse generalmente a mayores de setenta y cinco años) o la última innovación: "mayores" no son acuñados para hacer referencia a la mayor influencia social de los ancianos (que está por verse) por el hecho de ser más (que es indudable), sino que estos términos son coetáneos del momento histórico en que esta población está más relegada del sistema productivo. Lejos de mi interés valorar aquí la bondad de esta medida. Pero en cualquier caso parece contradictorio que sean los gobernantes de los estados del bienestar los que más hablan del apocalipsis productivo y de la quiebra de los sistemas de seguridad social como consecuencia del envejecimiento, sin que exista correspondencia entre los discursos y los hechos (salvo tímidos y no siempre afortunados intentos). No sabemos si esa actitud de grandilocuencia carastrofista estatal, ya de por sí, tiene caracter disuasorio sobre las magras pensiones, o si simplemente es un ejercicio de audacia gubernamental para justificar sus esfuerzos y sus desvelos para con los viejos.

\section{GENERACION Y VEJEZ}

Un cierto humanitarismo siempre bienintencionado quiere hacer ver que "la vejez" es un "estado mental subjetivo" del que la persona anciana puede sustraerse con buenas dosis de vitalismo, motivación y buena voluntad. Este discurso es polivalente, ya que todos podemos estar de acuerdo con él, pues en efecto en parte es así, pero los condicionantes objerivos una vez más no son idénticos para todos los viejos, y éstos no deben ser olvidados dentro de una sociología de la vejez. Desde luego si para algo sirve la sociología es para que, a partir del conocimiento de la realidad, se pueda actuar sobre los factores sociales objetivos que generan ciertas situaciones o uestados de ánimo".

El concepto más sociológico (y concreto) de cuantos podemos manejar es el de "generación". Concepto a la sazón nada sencillo y del que se han ocupado muchos clásicos de la sociología como son los casos de Comte y Mamhein (Attias-Donfut, Cl., 1991, pp 19-30), pero en el que se conviene ocupa alrededor de treinta años, o dicho de otra manera es la resultante de dividir en tres tercios la vida de un sujeto hipotéticamente longevo. Así nos encontraríamos con los menores de treinta (nietos), los comprendidos entre treinta y sesenta años (padres) y los mayores de sesenta (abuelos).

Dentro de la sociología, el concepto de "generación" es particularmente complejo, pues de él se pueden derivar - y se derivan - rasgos comúnmente compartidos por un grupo de sujetos de una determinada franja de edades. 
Bases y fundamentos para una aproximación sociológica a la vejez

Puede resultar fácil, de esta manera, impostar lo que de historia común hay, y olvidar las diferencias sociales que existen -y muy importantes- entre sujetos de una misma generación. En el interior de las generacioncs, las hay con mayores y con menores diferencias. Un abuso exacerbado de este concepto en el análisis sociológico (que en el fondo es el de la temporalidad), puede llevarnos a exagerar lo común en detrimento de otras diferencias endógenas sustanciales a efectos del mencionado análisis. Y por otra parte, frecuentemente ocurre la instrumentalización (más o menos consciente, según los casos) de este concepto a modo de cortina de humo para disipar las diferencias antes aludidas dentro de una sociedad o de una misma generación. Con esto no queremos restar importacia - que la tienen y mucho- a las diferencias intergeneracionales dentro de los análisis de estratificación social. Dentro de estos mismos análisis las diferencias se producen entre unos «coetáneos" con otros de diferentes generaciones, y entre los mismos coetáneos entre sí.

Comte señalaba en treinta años el tiempo que tardaba en pasarse de una generación a otra, y destacó el carácter social (y sociológico) del concepto de generación, ya que éste hace referencia a fenómenos de la vida social fundados en la adhesión unánime a ciertas nociones sociales fundamentales, y no a fenómenos de la vida familiar o de la biografía individual. Autores como Dilthey hacen hincapié en cómo la "coetaneidad" o contemporeidad (coincidencia en el tiempo) de individuos - que componen una generación- da lugar a relaciones profundas entre esos sujetos. Entre las muy abundantes teorías sobre las generaciones, algunas resultan particularmente interesantes desde el punto de vista conceptual, como es el caso de las generaciones histórico-sociales de Ortega y Gasset, a las que dentro de su teoría sobre el particular, las sitúa dentro de una zona temporal de quince años.

Como destaca Amando de Miguel, una generación, sin embargo, está compuesta por diferentes estratos, cohortes o promociones de población (De Miguel, A., 1987, pp. 35-36). Así, referido a la generación que nos ocupa (la de los viejos o ancianos), podemos convenir - y no es nada novedoso el descubrimiento-, la existencia de diferentes "grupos" de viejos desde la perspectiva sociológica. Desde la demografía también los hay (en atención a las variables poblacionales básicas) sin embargo, cierros discursos instrumentan o se sirven de dicha perspectiva para inferir y destacar el rasgo hegemónico y unificador de la "tercera edad": "la edad". He de reconocer que a mí, esta caja de pandora o saco de las sorpresas con que se nos sirve la "tercera edad" como un "todo" que se diferencia del otro "todo social" (niños-estudiantes por una parte, y los activos por otra) me preocupa. No alcanzo a entender bien ese afán "unificador" sobre la tercera edad. Pero lo cierto y verdad es que dichos discursos del mélange, a fuer de integradores, introducen una cortina de humo en las notables diferencias que existen entre los viejos. 
"Papers": Revista de Sociologia

Siempre han existido longevos (tantos como hoy). Como señala Amando de Miguel "...en contra de lo que se cree, no es que la longevidad sea ahora mayor, sino que la población envejece... La vida de los viejos no se ha alargado sustancialmente en las últimas décadas y siglos: no hay ahora más centenarios que antes" (De Miguel, A., 1987, pp. I.243); dicho de otra manera, el peso relativo de longevos sobre el total de ancianos no es hoy mucho mayor que to fue en épocas pasadas. Lo que si que ocurre es que hay más viejos (por la disminución de las tasas de mortalidad para todas las edades), pues más gente llega a la vejez.

Lejos de las concepciones que ven la vejez como un "grupo social" (v. g.: Arethe, Rose, Peterson) hemos de insistir una vez más que ésta es una "situación social" socialmente devenida, cn la que se observan, entre otras, diferencias básicas tales como: las de posición y estatus social, las de hábitos y estilos de vida, las propias diferencias generacionales entre elios, así como las estrictamente biográficas. Entre tantas diferencias, el accidente de la "edad" produce - faltaría más - rasgos comunes, pero ¿̇suficientes para ahogar o sofocar análisis de mayor calado social como pueden ser los referidos a estratificación social?

Las diferencias entre los viejos son de "estructura social", $y$ por mor del periodo histórico que les tocó vivir a los ancianos españoles de hoy (el más joven nació en el año 1930 y de ahí para abajo) esas diferencias sociales son más que relevantes. Eso, claro está, no sólo se traduce en el patrimonio que poseen y en las pensiones que perciben, sino en aspectos también claves como son su hontanar cultural, sus biografías, sus perspectivas y, lo que es más destacable, su "esperanza de vida» y su «salud". Y de tal suerte son importantes las «diferencias" que la administración española ha tenido que intervenir en niveles impensables hoy en otros países desarrollados a través de las pensiones "asistenciales" $y$ "no contributivas", no tanto para poner equidad, cuanto para "racionalizar" y administrar la pobreza. Y aún una diferencia mucho más relevante que introduce mayor diversidad entre los' ancianos: la territorial. Las diferencias espaciales son notables entre los ancianos de España. Tendremos ocasion de verlo más adelante. Estas diferencias territoriales se explicitan tanto en los aspectos cuantitativos (proporción de ancianos en las diferentes comunidades autónomas o en cualquier otra unidad tcrritorial) como en los cualitativos (instrucción, renta, salud, familia, etc.). De esta manera, la edad aparece como un sesgo altamente destacado en cualquier estudio de estructura social que queramos abordar, máxime en países, que como España, ejercen y desarrollan tardiamente los dividendos del estado social.

Volviendo al concepto sociológico de base, "la generación", introduce cierta claridad ( $y$ también complejidad) en lo de por sí nebuloso: "la vejez". La generación es ante todo presente inexcusable y pasado objetivo. Por una parte se vive el "accidente" colectivo de la edad, de la jubilación, de los achaques y de cierta "segregación" social. 
La "historicidad" que incorpora al análisis de la población el concepto de "generación" es importante, pues el envejecimiento es colectivo y también individual. Al menos este concepto hace distingos biográficos generales (que no es poco), y diferenciadores con respecto a las otras generaciones. Francisco Ayala dice de la "generación" que es "el estabón sobre el que engrana el proceso histórico-social; en ella puede encontrarse la unidad histórica más elemental y, por consiguiente, también el concepto cardinal de la sociologían. (Ayala, F., 1984, p. 239), pero sin embargo, reconoce Ayala: "es un concepto que nuestra ciencia (la sociologia) ha sometido a elaboración todavía deficiente» (ibidem, p. 240). Y tiene razón el maestro Ayala, pues al final el «accidente" biológico de pertenecer a una generación explica la "historicidad" o historia colectiva de los sujetos de una generación, pero no explica la diversidad de elos. En suma, el concepto de "generación" unifica biográficamente, pues como él indica, "tomada en su conjunto, una generación se realiza en el vivir, y lo que la distingue de las demás es su estilo de vida" (ibídem, p. 247), pero sin embargo no remarca las diferencias. La sociología es desde luego la ciencia de lo común (léase objetiva), pero también de la "diferencia" (léase subjetiva) aunque toda diferencia tenga su raíz social y su parte objetiva. Como señala Ma Ángeles Durán: "La "generación", tiene, pues doble dimensión o dos formas posibles de vinculación al tiempo: la "verticalidad", en cuanto succsión de descendientes (padre, hijos, nietos, etc), y la "horizontalidad" en la coexistencia en un mismo momento del tiempo de individuos de distintas edades (Durán, M. A., 1986, p. 104).

Los asuntos generacionales son importantes en todas las edades, pero el paso del tiempo da y dará uri "contenido" social a cada generación. De esta manera, los viejos de hoy, en atención a su aspecto físico (salud) como en atención a algunos grandes indicadores de estratificación social: renta, instrucción, hábitat, son diferentes a los que hubo hace treinta años, y serán diferentes a los que lleguen a esa edad dentro de otros treinta.

Pero con independencia de si los viejos/as (sobre todo las segundas) son muchos o pocos, lo cierto y verdad es que los ancianos han alcanzado una proporción y un volumen total en las sociedades que se han constituido en un problema social, "por primera vez los viejos y los viejos/as se han hecho visibles en el mundo y sus necesidades y problemas comienzan a ser las necesidades y problemas de la sociedad" (Bazo, M.T., 1990, p. 2). Todo esto es cierto, pero no sólo es el número, sino sus estado. España se engancha demasiado rápida a veces al carro de la modernidad teórica, olvidando las deficiencias de nuestro estado de bienestar. En los ancianos estas deficiencias afloran más que en ningún otro lugar, a pesar de que las economias domésticas -las familias- han sofocado y aliviado al Estado de acciones de mayor envergadura para con los ancianos, pues ellos padecieron más que ningún otro sector las 
"Papcrs": Revista de Sociologia

limitaciones de nuestro estado benefactor. Justamente la identidad del anciano proviene como arriba señalamos de su situación social objetiva de escasa relevancia social así como de su "condición" de pobreza potencial. Como señala $M^{a}$ Ángeles Durán: «El sentimiendo de conciencia generacional que indudablemente existe entre los ancianos proviene en gran parte de su situación de penuria». Al ser cada vez más una categoría administrativa, es inequívoca una cierta transformación en "grupos sociales" (en plural), que están "dotados de una consciencia generacional y facilidades para la interacción que no tuvicron en épocas anteriores (por ejemplo, mediante la obligatoriedad de la jubilación, la coincidencia en los locales de cobro de pensiones, en el uso de locales específicamente destinados a ellos, residencias y actividades organizadas, etc." (Durán, M. A., o.c., p. 110 ).

Dentro de la teoría sociológica sobre la vejez dominan los enfoques que prestan especial interés al comportamiento del anciano como "actor", o al de los ancianos como "grupo" producto de una peculiar "subcultura" propia de la edad (Mishara, B. L., Riedel, R. G., 1984.). Particularmente curiosas resuItan en esta línea las tesis de Arethe sobre el anciano como grupo social segregado, donde las circunstancias o características comunes de los ancianos (v. g.: aislamiento) les lleva a su particular aislacionismo. Por otra parte, autores como Riley, no se cansan de insistir en las bondades de estudiar a los ancianos utilizando una estratificación elaborada según la edad, en vez de una estratificación hecha por estatus y menos por clases sociales. Particularmente interesantes resultan las tesis de Archley, en tanto que subraya que la vejez es una "continuidad" con estadios anteriores de la vida. De esta manera la "adaptación" social a la nueva situación se produce de forma diferente según los sujetos. Otros autores, como es el caso de Streib, se permiten muy sensatamente cuestionar la entidad de los ancianos como grupo social con entidad autónoma y con conciencia de pertenencia. Según Streib (1965, p. 213) "en términos estrictamente sociológicos, las gentes de edad constituyen un agregado estadístico o categoría social, pero no un auténtico grupo".

Sin embargo, un aspecto de suma importancia - y que escapa a la extensión de estas páginas - a efectos de conocer la sociología de la diferencia es: la desigual autopercepción de la situación de anciano que tienen los sujetos incursos en esas edades. Ciertamente que los determinantes objetivos y subjetivos de la percepción de uno mismo frente a los demás son múltiples, pero no hemos de negar la importancia (y el interés) que a efectos analíticos del fenómeno tienc este hecho. Julio Iglesias de Usell nos aporta pistas sobre un hecho de sumo interés a la hora de asignar funciones sociales al anciano en el seno de la familia. La figura del abuelo, en efecto, ha sido transcendental en las sociedades tradicionales, sobre todo en familias extensas y polinucleares. A diferencia de lo que ocurría en periodos no lejanos de la historia europea y 
española, hoy la mayoría de niños conocen a sus abuelos (y cada vez más a sus bisabuelos). Bien, pues sin embargo el anciano también se ve expropiado de su papel socializador de los niños en la familia. Sometido a una relación relativamente distante de sus nietos y segregado de la producción directa, su círculo relacional está cada vez más circunscrito a personas de edad similar.

En esta misma línea y buscando las bases de una sociología de la ancianidad, aparece como asunto de sumo interés el conocimiento de los procesos de interiorización por parte de los ancianos de "su» realidad social objetiva. Esta interiorización de la realidad se impone socialmente al anciano y es producto del juego de fuerzas resultante de la "imagen" real y de unas potenciales y teóricas resistencias. Siendo la "imagen" la parte dura de la representación (Sánchez Vera, P., 1987). De csta manera resulta especialmente importantc la perccpción-representación que el anciano se hace de uese grupon. Por otra parte el anciano mantiene inexcusablemente una relación amor-odio con el grupo de ancianos, pues si de un lado rechaza la pertencia al mismo - los ancianos son «los otros"-, son mucho los elementos comunes de los que participa.

\section{VEJEZ Y TANNATOS}

La vejez, no cabe duda, se presenta más próxima al anciano. Por próxima, el anciano pierde temor a la muerte. La pérdida frecuentemente de su cónyuge introduce un vacío norable que aproxima al anciano a la muerte. Sin embargo en la vida social contemporánea se produce una banalización de la muerte a la vez que se marcan cada vez más las distancias y los temores, a diferencia de lo que históricamente ha ocurrido (Artés, P., 1992).

La sociedad occidental contemporánea pone "distancia" físico-lingüística y "simbólica" con la muertc. Esto es, retrasándola al máxino - faltaria más-; por eso la negación-ocultación de la "vejez" a través del lenguaje (tercera edad, mayores...), y la "exclusión" (Hert, R, 1990) de todo lo que la recuerde y/o acerque. Los procesos colectivos de representación social se tornan truculentos y mágicos en determinados asuntos. En la vejez o en la ancianidad (senectud es término menos social y más geriátrico) se sustituye o suplanta lo central o la esencia de la misma (el hecho de envejecer) por una generalización social con visos de inmediatez. La "tercera edad" es el resultante de la suma aritmética de $1+1+1$ o de la concatenación de los periodos vitales, pero aún tiene cierto contenido de "fase terminal" o lo que es lo mismo de dramatismo. Sin embargo el término "mayores" que empieza a suplantat al anterior - y al que auguro rápido y profundo éxito a tenor del vigor y la decisión con que la administración lo ha empezado a utilizar - es la generalización de lo genérico. 
"Papersn: Revista de Sociologia

Ciertamente que la presencia de la muerte ha sido uno de los hechos que más han determinado el mundo simbólico y representacional de las sociedades. I a convivencia conidiana con el fenómeno restaba valor a la vida y consiguientemente al sujeto. La gran morralidad infantil hacía bautizar a los recién nacidos para librarlos del pecado original en la religión carólica. A mayor edad, las probabilidades de fallecer se multiplican, esto es: la muerte se aproxima. La vejez se "estigmatiza" de ese principio en mayor medida que las edades más jóvenes. La imagen totalizante y totalizadora de las instituciones de ancianos (Goffman, E.; Barenys, M. P., I99I) viene marcada y legitimada por el estigma de la muerte próxima; de esa manera nada raro resulta la segregación social de los ancianos en esas residencias o instirtuciones "ad hoc".

Con el incremento de la esperanza de vida, se produce una importante victoria de la "ciencia» sobre la umuerte", entrando aquí en contradicción esa victoria de la ciencia con la racionalidad del sistema (Baudriłlard, 1980). Como señala este autor (ibídem, p. 191) "las tierras conquistadas en esta marcha de la muerte son socialmente desérticas... La tercera edad expresa bien lo que significa: es una especie de Tercer Mundo... No es más que un trozo de vida marginal, asocial, un gueto, una prórroga... Se trata de una liquidación de la vejez. A medida que los vivos viven más largamente, a medida que le "ganan" a la muerte, cesan de ser reconocidos simbólicamente. Condenada a una muerte que retrocede constantemente, esta edad pierde su estatuto y sus prerogativas... La esperanza prolongada de vida no ha desembocado sino en una discriminación de la vejez, que deriva a su vez de la discriminación de la muerte misma. Lo "social" aquí también ha cumplido su tarea. Has hecho de la vejez un territorio social, han socializado esta porción de vida encerrándola en sí misman (ibídem).

Desde luego dentro de la teoría sociológica, el tema de la muerte ha sido relativamente fecundo --v.g: Mannheim, Parsons, Durhheim-, sin embargo está por hacerse una verdadera sociología de la muerte, esto es con un objeto propio que no la desvincule del análisis sociológico global. La edad en este caso, como la clase social, así como otras variables de carácter cultural diversas, es un factor más - muy importante desde luego-, pero puesto en relación con otros tantos. Al igual que la enfermedad, la muterte es separada de la vida social simbólica y físicamente (Foucault). También en la enfermedad como en la salud, la clase social es un factor al que no se le ha prestado la debida atención, y es una variable altamente significativa de los estados de salud, incluyendo naturalmente su relación con las edades avanzadas (Rodríguez, A., De Miguel J., 1990, pp. 66-95).

Para terminar, una fundamentación sociológica de y sobre la vejez debe partir, como antes señalamos, de las bases sociales por las que la colectividad percibe y se representa esa "condición" (la de anciano). Pero junto a esto, es 
fundamental resaitar que hablamos de "poblaciones ancianas" heterogéneas. Indagar en la diferenciación de estas poblaciones es buscar caminos sociológicos adecuados para la verdadera "identidad" del anciano y de la vejez. A pesar de los rasgos concurrentes que cualifican a la tercera edad y que conllevan aspectos comunes o de una cierta ( $y$ relativa) identidad colectiva, sin embargo, conviene resaltar que esa identidad es culural e ideológica y, desde luego, lo es también concreta.

\section{BIBLIOGRAFÍA}

Arbelo C, A.; Hernández, G.; Arbelo L., A. (1986). Demografia sanitaria de la edad adulta. Madrid, Ministerio de Sanidad y Consumo.

Ariess. Ph. (1992). El hombre ante la muerte. Madrid, Taurus.

Attias-Donfut, Cl. (1991). Generations et ages de la vie. Partís, Press Universitaires de France, pp. 19-30.

Ayala, F. (1984). Tratado de Sociologia. Madrid, Espasa-Calpe.

Barenys, Ma, P. (1991). Residencias de ancianos. Barcelona, Fundació Caixa de Pensions.

Barenys, Ma P. (1992). "Año 1993. Año Europeo de las personas de edad avanzada y de la solidaridad entre las generaciones". Rev. Gerontologia, $V_{0}$ 2, No2, pp. 75-76.

Baudrillard, J. (1972). "I. a moral de los objetos. Función-signos y lógica de clasem, en: la significación del entorno. Barcelona, C.O. de Arquitectos de Cataluña y Baleares. Baudrillard, J. (1976). La génesis ideologica de las necesidades. Barcelona, Anagrama. Baudrillard, (1978). J. Cultura y simulacro. Barcelona, Kairós.

Baudrillard, J. (1980). El intercambio simbblico y la muerte. Barcelona, Monte Ávila Editores, pp. 191-192.

Bazo, M.T. (1990). La sociedad anciana. Madrid, C.I.S., p. 2.

Bourdieu, P. (1988). La Distinción (criterio y bases sociales del gusto). Madrid, Taurus. Berger, P. L., Luckmann, T. (1972). La construcción social de la realidad. B. Aires, Amorrortu.

Castillo Castillo, J. (1989). "El creciente cometido instrumental del trabajo". Rev. Sistema, $n^{\circ} 88$, enero, pp. 93-103.

De Miguel, A. (1986), "L.os vie; os en la sociedad actual», cn VV. AA. Sociedad y Sociologia, Barcclona, Salvat, p. 1243.

De Miguel, A. (1987). La España Cílica. Madrid, Fundación Banco Excerior, pp. 35-36.

Durán, Ma A., (1986). "Las Bases biológicas de la cstructura social", en Salusciano del Campo, Tratado de Sociologria Vol. 1, Madrid, Taurus, p. 110.

Glendenning, F. (cd.) (1985). Educational Gerontology. International Perspectives. Croom Helm. Londres, pp. 31-53 (referido a clases de educación gerontológica. ¿qué es la educa. gerontológica?) 
"Papers": Revista de Sociologia

Haut Conseil de la Population et de la Famille (1989). Girad, P. et Lion, E. (ed.). Vieillissement et Emploi. Veillissement et Travail. Documentation Française. Paris.

Hertz, R. (1990). La muerte (contribución a un estudio sobre la representación colectiva de la muerte). Madrid, Alianza, pp. 13-102.

Izquierdo, A. (1985). "Ideologías aciagas sobre el crecimiento mundial de la población", en Monreal, J. Población y Economia (la poblacion en el aniversario de Maltbus). Murcia, Universidad de Murcia. Aula de Humanidades, pp. 39-49.

Lefebvre, H. (1984). La vida cotidiana en el mundo moderno. Madrid, Alianza.

Marrin Moreno, J., De Miguel, A. (1979). Universidad, fábrica de parados. Madrid, $\mathrm{Vicens.}$

Martins, H. (1992). "Tiempo y tcoría sociológica", en Ramos 'Torres, R. Tiempo y sociedad, Madrid, C.I.S., p. 183.

Mishara, B. I., Riedel, R. G. (1984). El proceso de envejecimiento. Madrid, Morata. Moncada, A. (1976). Sociología de la Educación. Madrid, Edicusa.

Moncada, A. (1979). La adolescencia forzosa. Madrid, Dopesa.

Palop Jonquéres, P. (1981). Epistemología genética y filosofia. Barcelona, Ariel.

Ramos Torre, R., (1992). Tiempo y Sociedad. Madrid, C.I.S.

Rodríguez, J. A.; De Miguel, J. M. (1990). Saludy poder. Madrid, C.I.S., pp. 66-84. Sagrera, M. (1992). El edadismo (contra jóvenes y viejos). Madrid, Ed. Fundamentos.

Sánchez Vera, P. (1987). "Anotaciones sobre la representación y la imagen del espacio". Cuadernos de Ciencia Politica y Sociologia, No 19, julio, Madrid, 1987, pp. $11-26$.

Sánchez Vera, P. (1990). Caracterización del colectivo de ancianos en la Comunidad Autonoma de la Región de Murcia (CARM). Orihuela, Patronato Angel Garcia Rogel. Caja de Ahorros del Mediterráneo (CAM), Roneo.

Sauvy, A. La población. (1960). Ed. Universitaria de Buenos Aires, B. A., pp. 126-128.

Sommet, R. (1974). Espacio y comportamiento individual Madrid, Instituto de Estudios de la Administración Local.

Streib, G. F. (1965). "Are the aged a minoricy group?", en Goulder, A., Miller, S. M. Applied Sociology. N. York, Free Press.

Turner, B. S (1989). El cuerpo y la sociedad (exploraciones en teoría social). México, F.C.E., pp. 57-89.

V. AA. (1968), La civilización del ocio. Madrid, Guadarrama, pp. 89-105.

VV. AA. (1981). Ocio y sociedad de clases. Barcelona, Fontanella. 